\title{
LETTER
}

\section{Our Priorities Are Not Evolving, but Our Strategies Are}

Kathryn J. Smith, PharmD, ${ }^{a}$ Craig D. Cox, PharmD, ${ }^{b}$ Eliza Dy-Boarman, PharmD,${ }^{c}$ Michael Gonyeau, PharmD,${ }^{\mathrm{d}}$ Kelly A. Lempicki, PharmD, ${ }^{\mathrm{e}}$ Cherie Lucas, PhD,${ }^{\mathrm{f}}$ John M. Lonie, EdD, ${ }^{\mathrm{g}}$ Mary Douglass Smith,

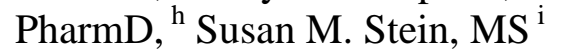

${ }^{\text {a }}$ University of Oklahoma, College of Pharmacy, Oklahoma City, Oklahoma

${ }^{\mathrm{b}}$ Texas Tech University Health Sciences Center, Jerry H. Hodge School of Pharmacy, Lubbock, Texas

${ }^{\mathrm{c}}$ Drake University, College of Pharmacy and Health Sciences, Des Moines, Iowa

${ }^{\mathrm{d}}$ Northeastern University, Bouve College of Health Science, Boston, Massachusetts

${ }^{\mathrm{e}}$ Midwestern University, Downers Grove, Illinois

${ }^{\mathrm{f}}$ University of Technology, Sydney, Australia

${ }^{\mathrm{g}}$ Long Island University, College of Pharmacy, Brooklyn, New York

${ }^{\text {h }}$ Presbyterian College, School of Pharmacy, Clinton, South Carolina

${ }^{i}$ Pacific University, School of Pharmacy, Hillsboro, Oregon

Corresponding Author: Kathryn J. Smith, University of Oklahoma, College of Pharmacy, 1110 N Stonewall Ave, Oklahoma City, OK 73117. Tel: 405-271-6878. Email: kathryn-j-smith@ouhsc.edu

Submitted May 19, 2021; accepted June 28, 2021; ePublished July 2021

Keywords: priorities, strategic planning, disruption, resilience, collaboration

To the Editor: Dr. Daniel Malcom's recent commentary "The Challenge of Coming to Terms with Evolving Priorities" resonated with us as we begin the process of recovering from the overwhelming number of personal and professional changes we've experienced in the wake of the COVID-19 pandemic. ${ }^{1}$ The disappointment described by Malcom and other faculty members in his department was faced by various institutions around the world. Goals and expectations have had to shift and we've all been forced to adjust. We agree with and want to amplify Malcom's recommendation to "resist the temptation to judge or overly criticize ourselves for failing to meet goals we set pre-pandemic". The stress and change brought by the pandemic has encouraged critical reflection, both individually and collectively, about where we are headed and how we will get there. That said, we would suggest strategies employed to meet personal and professional goals have evolved rather than our priorities or values as a result of the pandemic.

Roadblocks and setbacks are unpredictable but expected in life. We have learned to "expect the unexpected." Malcom states "Systematically reevaluating our priorities based on new and evolving events and circumstances in our lives is a natural part of growth and development." But what if we were confident in our priorities and values before these new events emerged and were able to use our values to guide us through or around these roadblocks? Think of this as preventative medicine: if you have a yearly check-up, you'll hopefully be able to identify problems and implement solutions earlier, hence avoiding costly acute care down the road. Identifying one's priorities and values in times of relative calm can provide clear navigation when the road becomes bumpy and unpredictable, whether it presents itself as a literal flat tire, not matching for a residency position at the end of pharmacy school or a global pandemic.

Organizations, as well as individuals, have had to adapt during this crisis. The ability to effectively adapt to changing situations depends on a number of factors, not the least of these is degree of resiliency. The ability to adapt and rebound from adversity is not something that can easily be measured or assessed. Having clear goals and values prior to a disconcerting event does not necessarily predict the post-event goals, values, and behaviors. But again, if the organization was clear and unified in their shared values and priorities prior to the pandemic, they may have had an easier time deciding what initiatives to prioritize during the crisis. Most health care organizations would say they prioritize quality of patient care. This value may have meant collaborating to put all of their efforts into caring for patients with COVID-19 but delaying the roll out of other planned initiatives (e.g., a new electronic health record system). Strategies used within the organization to maintain quality of care likely changed due to the pandemic as well. Similarly, within our own academic institutions, we have each observed increased collaboration and innovation in the wake of the pandemic that may have taken much more time to develop under "normal" circumstances.

As faculty and mentors, we have the opportunity to assist our students and trainees in identifying their own priorities and values, enabling them to be equipped with guiding principles for decision making when setbacks arise. 
Additionally, as educators we should also model and share with our students when we have to adapt or change on the fly. Activities designed to improve self-awareness such as emotional intelligence, CliftonStrengths and other character trait inventories can help us understand who we are, what we value, and how we present ourselves. ${ }^{2}$ Knowledge of one's guiding values or priorities can serve as a compass, pointing you towards your final destination, even if you're momentarily on a detour. Students often believe there is only one path to their "dream job", when in fact, there are often many strategies to reach the same outcome. We also should work within our institutions to identify what priorities have remained during this challenging time and reexamine the strategies it took to get here. There may not be a better time to challenge the "way we've always done it" than following a time of still achieving our goals in completely novel ways.

\section{References}

1. Malcom DR. The challenge of coming to terms with evolving priorities. Am J Pharm Educ. 2020; 85(4): Article 8664.

2. Gallup Website: How to Help Students Thrive Using CliftonStrengths for Students. https://www.strengthsquest.com/192611/resources.aspx Accessed 18 May 2021. 